\title{
Effects of Cholecystectomy on the Kinetics of Primary and Secondary Bile Acids
}

Frieder Berr, Frans Stellaard, Ekkehard Pratschke, * and Gustav Paumgartner

Departments of Medicine II and *Surgery, Klinikum Grosshadern, University of Munich, Federal Republic of Germany

\begin{abstract}
Removal of the gallbladder is thought to increase formation and pool size of secondary bile acids, mainly deoxycholic acid (DCA), by increased exposure of primary bile acids (cholic acid [CA], chenodeoxycholic acid [CDCA]) to bacterial dehydroxylation in the intestine. We have tested this hypothesis by simultaneous determination of pool size and turnover of DCA, CA, and CDCA in nine women before and at various intervals after removal of a functioning gallbladder. An isotope dilution technique using marker bile acids labeled with stable isotopes $\left({ }^{2} \mathrm{H}_{4}-\mathrm{DCA},{ }^{13} \mathrm{C}-\mathrm{CA},{ }^{13} \mathrm{C}-\mathrm{CDCA}\right)$ was used. After cholecystectomy, concentration and output of bile acids relative to bilirubin increased $(P<0.02)$ in fasting duodenal bile and cholesterol saturation decreased by $27 \%(P<0.05)$ consistent with enhanced enterohepatic cycling of bile acids. Three months after removal of the gallbladder bile acid kinetics were in a new steady state: pool size and turnover of CDCA were unchanged. Synthesis of CA, the precursor of DCA, was diminished by $37 \%(P=0.05)$, probably resulting from feedback inhibition by continuous transhepatic flux of bile acids. The fraction of $\mathbf{C A}$ transferred after $7 \alpha$-dehydroxylation to the DCA pool increased from $46 \pm 16$ to $66 \pm 32 \%(P<0.05)$. However, this enhanced transfer did not lead to increased input or size of the DCA pool, because synthesis of the precursor CA had decreased.
\end{abstract}

\section{Introduction}

The effects of cholecystectomy on biliary physiology have recently received new attention, as alternative conservativetreatment strategies for cholesterol gallstones have been developed $(1,2)$. Cholecystectomy offers an excellent chance of curing gallstone disease permanently. Concern, however, has risen about the hypothesis, that cholecystectomy might in-

Parts of this work were presented at the IXth International Bile Acid Meeting, Basel, October 1986 and at Annual Meeting of the American Association for the Study of Liver Diseases, Chicago, IL, November 1986. Summaries of the interim results were published in 1987. Bile Acids and the Liver. Paumgartner, G., A. Stiehl, and W. Gerok, editors. MTP Press Ltd., Lancaster, UK. 281-283. Summaries were also published in 1986. Hepatology (Baltimore). 6:1 159. (Abstr.)

Dr. Frans Stellaard's present address is Free University Hospital, Department of Pediatrics, De Boelelaan 1117, NL 1007 MB Amsterdam. Address reprint requests to Dr. Frieder Berr, Medizinsche Klinik II, Klinikum Grosshadern, Marchioninstrasse 15, D-8000 Muenchen 70, Federal Republic of Germany.

Received for publication 15 April 1988 and in revised form 19 December 1988.

J. Clin. Invest.

(c) The American Society for Clinical Investigation, Inc.

0021-9738/89/05/1541/10 $\$ 2.00$

Volume 83, May 1989, 1541-1550 crease formation and pool size of secondary bile acids, mainly DCA (3-5). Several studies have reported an increased incidence of colonic neoplasia 6-15 yr after cholecystectomy $(6-8)$. Even though not confirmed by others $(9,10)$, this observation has been linked to the cocarcinogenic role of excess DCA observed in animal experiments $(11,12)$.

The literature on the effects of cholecystectomy on hepatobiliary physiology is still controversial. After removal of the gallbladder, cycling of primary bile acids is enhanced (13). Turnover of primary bile acids and deoxycholic acid (DCA) ${ }^{1}$ content of bile were increased in one followup study (3), but DCA did not increase in bile in another larger followup study (14). Studies relying on group comparison of patients with and without gallbladder have also reported controversial findings on DCA content of bile $(4,5,15)$; but the effect of cholecystectomy on size and turnover of the DCA pool has not yet been studied in the same subjects before and after surgery.

We, therefore, investigated the effects of cholecystectomy on biliary lipid composition and on the kinetics of the major three bile acids (cholic acid [CA], chenodeoxycholic acid [CDCA], DCA) in the same patients before and at various intervals after cholecystectomy. Patients with well-functioning gallbladders were selected for this objective.

\section{Methods}

Patients. All patients had been referred to this hospital for elective cholecystectomy. They had suffered from occasional episodes of biliary pain, but were otherwise healthy. The protocol had been approved by the Ethics Committee of this hospital. All participants gave their written informed consent before the study. Only women $<50 \mathrm{yr}$ of age (16) were studied. Criteria for exclusion from the study were obesity ( $>125 \%$ ideal body weight), hyperlipidemia (serum cholesterol $>250$ $\mathrm{mg} / \mathrm{dl}$; serum triglycerides $>200 \mathrm{mg} / \mathrm{dl}$ ), diabetes mellitus, cholangitis, diseases of the intestine or the liver (elevated alanine aminotransferase or aspartate aminotransferase, prolonged prothrombine time, clinical or sonographic evidence) as well as administration of antibiotics, lipid-lowering drugs, or steroid hormones within the last 4 wk. Patients were selected who had a functioning gallbladder, documented by visualization and by contraction on oral cholecystography or ultrasonography during cholecystokinin (CCK) infusion, and a rather low ratio $(<0.33)$ of stone size to gallbladder size. Except for subject A.E., all had radiolucent stones. Histology yielded no (E.G., K.F.) or minor-tomoderate grade chronic cholecystitis. Patient characteristics are given in Table I. All patients were studied as outpatients while on their customary diet. Cholesterol intake was moderate and not different before and after cholecystectomy (Table I). Body weight and stool frequency did not change. Patients were classified according to cholesterol content of gallstones: group A $(n=6)$ had cholesterol gallstones as defined by a cholesterol content of $>60 \%$ on a dry weight basis. Patients in group B $(n=3)$ had either mixed gallstones (A.E.) or no stones. None had common duct stones.

Study protocol. All patients were studied within $10 \mathrm{~d}$ before operation and again at $6 \mathrm{wk}$ and $3 \mathrm{mo}$ after cholecystectomy. Six of the nine

1. Abbreviations used in this paper: $\mathrm{CA}$, cholic acid; CDCA, chenodeoxyxholic acid; DCA, deoxycholic acid; FTR, fractional turnover rate. 


\begin{tabular}{|c|c|c|c|c|c|c|c|c|c|c|c|c|c|c|c|}
\hline & \multirow{3}{*}{$\frac{\text { Age }}{y r}$} & \multicolumn{3}{|c|}{ Body weight } & \multirow{3}{*}{ Diagnosis } & \multicolumn{4}{|c|}{ Gallstones } & \multicolumn{2}{|c|}{$\begin{array}{l}\text { Dietary cholesterol } \\
\text { intake }\end{array}$} & \multicolumn{2}{|c|}{ Serum lipids } & \multicolumn{2}{|c|}{ Stool frequency } \\
\hline & & \multicolumn{2}{|c|}{$\begin{array}{c}\text { Before } \\
\text { operation }\end{array}$} & \multirow{2}{*}{ 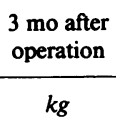 } & & \multicolumn{3}{|c|}{ Volume } & \multirow{2}{*}{$\begin{array}{c}\begin{array}{c}\text { Cholesterol } \\
\text { content }\end{array} \\
\% d r y w t\end{array}$} & \multirow{2}{*}{$\begin{array}{c}\begin{array}{c}\text { Before } \\
\text { operation }\end{array} \\
m g\end{array}$} & \multirow{2}{*}{$\begin{array}{l}3 \text { mo after } \\
\text { operation }\end{array}$} & \multirow{2}{*}{$\begin{array}{c}\begin{array}{c}\text { Choles- } \\
\text { terol }\end{array} \\
m g /\end{array}$} & \multirow[t]{2}{*}{$\begin{array}{l}\text { Triglyc- } \\
\text { erides }\end{array}$} & \multirow{2}{*}{$\begin{array}{c}\begin{array}{c}\text { Before } \\
\text { operation }\end{array} \\
d\end{array}$} & \multirow{2}{*}{$\begin{array}{l}3 \text { mo after } \\
\text { operation }\end{array}$} \\
\hline & & $\% I B W^{*}$ & $k g$ & & & $n$ & $m l$ & $\%$ & & & & & & & \\
\hline \multicolumn{16}{|l|}{ Group A } \\
\hline w.w. & 39 & 125 & 71 & 69 & GB stones & 2 & 3.0 & 15.8 & 79 & 627 & 500 & 227 & 151 & 0.6 & 1.0 \\
\hline H.A. & 44 & 103 & 67 & 69 & GB stones & 2 & 7.5 & 23.4 & 65 & 267 & 466 & 160 & 56 & 1.0 & 1.0 \\
\hline A.N. & 38 & 119 & 70 & 72 & GB stones & 8 & 3.5 & 17.5 & 83 & 350 & 401 & 233 & 184 & 0.6 & 1.0 \\
\hline C.S. & 44 & 109 & 71 & 68.5 & GB stones & 2 & 1.5 & 3.9 & 78 & 537 & 442 & 239 & 129 & 1.0 & 1.0 \\
\hline E.B. & 38 & 102 & 55 & 53 & GB stones & 4 & 0.5 & 1.1 & 73 & 349 & 323 & 189 & 130 & 1.0 & 0.6 \\
\hline C.v. & 35 & 118 & 76 & 73 & GB stones & 40 & 1.1 & 6.9 & 70 & 207 & 343 & 156 & 90 & 1.0 & 1.0 \\
\hline$x$ & 39.7 & 112.7 & 68.3 & 67.4 & & & 2.8 & 11.4 & 75 & 390 & 413 & 193 & 122 & 0.87 & 0.93 \\
\hline SD & \pm 3.6 & \pm 9.4 & \pm 7.2 & \pm 7.3 & & & \pm 2.6 & \pm 8.8 & \pm 7 & \pm 161 & \pm 70 & \pm 36 & \pm 50 & 0.21 & 0.19 \\
\hline \multicolumn{16}{|l|}{ Group B } \\
\hline E.G. & 44 & 101 & 52 & 53 & GB polyp & 0 & - & - & - & 196 & 256 & 218 & 71 & 1.0 & 1.0 \\
\hline K.F. & 47 & 116 & 66 & 64 & $\begin{array}{l}\text { Polycystic liver } \\
\text { disease }\end{array}$ & 0 & - & - & - & 253 & 272 & 232 & 110 & 1.0 & 1.0 \\
\hline A.E. & 36 & 96 & 48 & 48.5 & $\begin{array}{l}\text { Mixed gallstones, } \\
\text { cystic duct stone }\end{array}$ & 15 & 0.5 & 2.0 & 19 & 213 & 348 & 208 & 87 & 0.75 & 1.0 \\
\hline$x$ & 42.3 & 104.3 & 55.3 & 55.2 & & & & & & 221 & 292 & 219 & 89 & 0.92 & 1.0 \\
\hline SD & \pm 5.7 & \pm 10.4 & \pm 9.5 & \pm 8.0 & & & & & & \pm 29 & \pm 49 & \pm 12 & \pm 20 & \pm 0.14 & - \\
\hline
\end{tabular}

GB, gallbladder. * Ideal body weight according to Statistical Bulletin \#40, Metropolitan Life Insurance Co., Nov.-Dec., 1959 . $\$$ Total gallstone volume as percentage of fasting gallbladder volume (by ultrasound). ${ }^{8} \mathrm{E} . \mathrm{B}$. had an aortic bioprosthesis for $1 \mathrm{yr}$ and took $50 \mathrm{mg}$ chlorthalidone daily.

patients were available for restudy at 9-12 mo after operation. Each time dietary cholesterol intake, stool frequency (over a period of $6 \mathrm{~d}$ ), and bile acid kinetics were assessed. Lipid composition of duodenal bile was checked the day before cholecystectomy and again after 7 wk. During cholecystectomy all gallbladder bile was collected for lipid analysis and the gallstones for cholesterol analysis.

Dietary protocols. During the study period, the patients kept a detailed daily record of food and beverage intake for $7 \mathrm{~d}$ (17). The records were evaluated by a dietitian for cholesterol intake using food tables (18). All patients were on their mixed diet with moderate cholesterol intake $(<700 \mathrm{mg} / \mathrm{d})$.

Bile acid kinetics. Pool sizes and turnover rates of CA, CDCA, and DCA were simultaneously determined from serum samples obtained over $4 \mathrm{~d}$ after oral intake of the marker bile acids, which were labeled with stable isotopes $\left({ }^{13} \mathrm{C} ;{ }^{2} \mathrm{H}\right)$. In the first three patients, only kinetics of CDCA and DCA were performed using ${ }^{13} \mathrm{C}$-labeled marker bile acids. Marker bile acids labeled with stable isotopes were purchased from Merck Sharp \& Dohme, Montreal, Canada with the following isotopic purities: $24-{ }^{13} \mathrm{C}$-DCA $91.5 \%{ }^{13} \mathrm{C} ; 2,2,4,4-{ }^{2} \mathrm{H}_{4}$-DCA $99.4 \%{ }^{2} \mathrm{H}_{4} ; 24-{ }^{13} \mathrm{C}$ CA $90 \%{ }^{13} \mathrm{C} ; 24-{ }^{13} \mathrm{C}-\mathrm{CDCA} 91.9 \%{ }^{13} \mathrm{C}$.

Materials, sample preparation, measurement of isotope ratios of individual bile acids using capillary gas liquid chromatography mass spectrometry, selected ion monitoring, and the calculation of bile acid kinetics from the decay curves of their isotopic enrichment have previously been validated and described in detail $(19,20)$. The mass ions $m / z 255$ and 259 were used for measurement of ${ }^{2} \mathrm{H}_{4} /{ }^{2} \mathrm{H}_{0}$ isotope ratios of DCA, $m / z 370$ and 371 for measurement of ${ }^{13} \mathrm{C} /{ }^{12} \mathrm{C}$ isotope ratios of DCA and CDCA, and $m / z 458$ and 459 for the ${ }^{13} \mathrm{C} /{ }^{12} \mathrm{C}$ isotope ratio measurements of CA (20). An example of a single kinetic study (A.N., before operation) is shown in Fig. 1.

Before oral intake of label a blood sample $(15 \mathrm{ml})$ was drawn to measure the isotope ratios of endogenous bile acids (i.e., the natural abundance of these isotopes). Between 6:00 and 10:00 p.m., $50 \mathrm{mg}$ of each marker bile acid $\left({ }^{13} \mathrm{C}=\mathrm{CA},{ }^{13} \mathrm{C}-\mathrm{CDCA},{ }^{2} \mathrm{H}_{4}\right.$-DCA) dissolved in 200 $\mathrm{ml} \mathbf{0 . 2 5 \%}$ sodium bicarbonate solution were simultaneously taken orally. On the next $4 \mathrm{~d}$, blood specimens for analysis were drawn once daily $1.5-3 \mathrm{~h}$ after the evening meal.
Calculation of bile acid kinetics. Natural abundance $\left(R_{0}\right)$ of ${ }^{13} \mathrm{C} /{ }^{12} \mathrm{C}$ isotope ratio in serum bile acids before administration of marker bile acids was $0.3691 \pm 0.0067$ for $C A$ and $0.3319 \pm 0.0072$ for $C D C A$; natural abundance of ${ }^{2} \mathrm{H}_{4} /{ }^{2} \mathrm{H}_{0}$ isotope ratio for DCA was $0.0054 \pm 0.0020$. Isotopic enrichment $(R)$ over natural abundance was converted to atoms percent excess (APE).

$\mathrm{APE}=\frac{R-R_{0}}{1+\left(R-R_{0}\right)} \times 100 \%$.

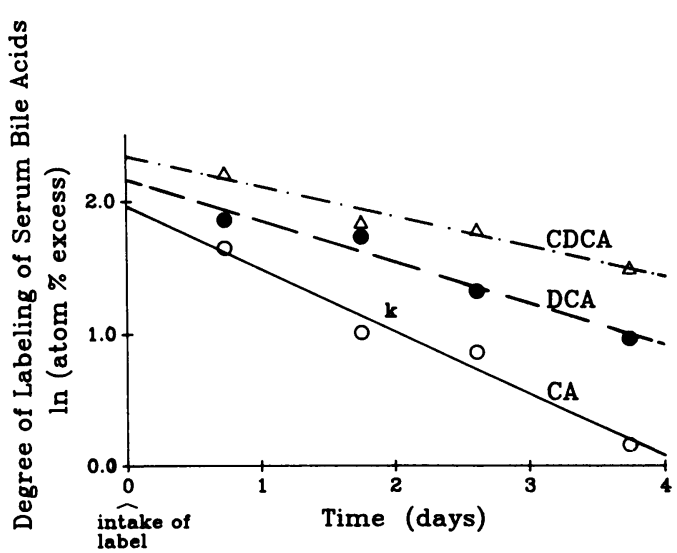

Figure 1. Simultaneous decay curves of $2,2,4,4-{ }^{2} \mathrm{H}_{4}-\mathrm{DCA}, 24-{ }^{13} \mathrm{C}$ $\mathrm{CA}$, and $24-{ }^{13} \mathrm{C}-\mathrm{CDCA}$ measured in serum of a patient with cholesterol gallstones (A.N., before cholecystectomy) after oral administration of $50 \mathrm{mg}$ of each label. Isotope ratios for the three bile acids were determined using gas liquid chromatography, mass spectrometry, and selected ion monitoring. The kinetics were calculated according to these formulas: pool size $=\left(\right.$ dose: $\left.\mathrm{APE}_{0} \cdot 100\right)-$ dose (in micromoles per kilogram); fractional turnover rate (FTR) $=k$ (in days $^{-1}$ ); synthesis rate $=$ pool size $\cdot$ FTR (in micromoles per kilogram per day). 
The In APE vs. time curve corresponded to monoexponential firstorder decay (19) with excellent fit (regression coefficient $r>0.90$ by linear regression analysis). Kinetics were calculated with the following equations (19):

Pool size $=\frac{\text { dose } \times b \times 100}{e^{a}}-$ dose

Synthesis rate $=$ Pool size $\times$ FTR,

where $a$ is the $y$ intercept of the APE decay curve, $b$ the degree of labeling (range 0.900-0.994) of the administered marker bile acid, and FTR (fractional turnover rate), the slope of the regression line. Pool sizes are reported as $\mu \mathrm{mol} \cdot \mathrm{kg}^{-1}$, FTR as $\mathrm{d}^{-1}$, and synthesis rates of primary bile acids or input rate of DCA as $\mu \mathrm{mol} \cdot \mathrm{kg}^{-1} \cdot \mathrm{d}^{-1}$.

To follow the transfer of ${ }^{13} \mathrm{C}$ label from administered $\mathrm{CA}$ marker to the DCA pool, the amount of excess ${ }^{13} \mathrm{C}-\mathrm{DCA}$ in the enterohepatic bile acid pool was estimated:

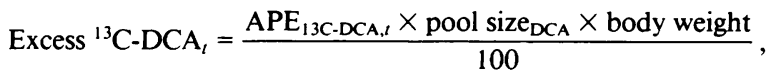

where $\mathrm{APE}_{t}$ was the respective APE in the sample drawn at time $t$ after intake of $50 \mathrm{mg}$ of ${ }^{13} \mathrm{C}-\mathrm{CA}$, and DCA pool size was estimated from decay of ${ }^{2} \mathrm{H}_{4}$-DCA.

Gallbladder motor function. On the day before cholecystectomy, the fasting volume of the gallbladder and its emptying in response to a CCK infusion (1.2 Ivy dog units $\mathrm{kg}^{-1} \cdot \mathrm{h}^{-1}$ for $50 \mathrm{~min}$ ) (21) was documented every 5 minutes for $50 \mathrm{~min}$ by ultrasound (Sonolayer B, Toshiba Corp., Tokyo). Serial volumes and emptying of the gallbladder were quantitated from longitudinal linear array images of the gallbladder (22).

Sampling of duodenal bile. After overnight fasting (12 h), the patients swallowed a thin Teflon duodenal tube equipped with a guiding wire for positioning. Correct positioning of the aspiration port in the proximal duodenum was initially checked by fluoroscopy and in later studies by aspiration of bile-rich duodenal fluid of $\mathrm{pH}>7.0$, provided the tube had been advanced $70-80 \mathrm{~cm}$. Unstimulated duodenal bile ( 3 $\mathrm{ml}$ ) was collected on ice. Subsequently CCK (Kabi-Vitrum, Stockholm) was infused intravenously and bile collected in 10-min intervals for $50 \mathrm{~min}$. The two darkest bile specimens, which were collected at $10-30 \mathrm{~min}$ of the infusion, were combined and a specimen $(3 \mathrm{ml})$ was taken. The remaining bile was returned to the duodenum at the end of the procedure. All bile specimens had been collected on ice, and stored in chloroform/methanol solution $(1: 2 \mathrm{vol} / \mathrm{vol})(0.5 \mathrm{ml}$ bile per $7.5 \mathrm{ml}$ solvent) for analysis.

Intraoperative specimens. All gallbladder bile was aspirated from the excised gallbladder into a sterile syringe, its volume measured and a specimen stored in chloroform/methanol solution. The volume of the gallstones was estimated by water displacement in a graded cylinder. Cholesterol content of the stones (percent dry weight) was determined by colorimetric analysis after grinding and isopropanol extraction of the debris (23).

Analysis of bile samples. Specimens in chloroform/methanol solution (corresponding to 50 or $100 \mu \mathrm{l}$ of bile) were analyzed by capillary gas liquid chromatography for individual bile acids (19). Bilirubin (24), cholesterol (25), and lipid phosphorus (26) in bile were assayed by colorimetric methods. The molar percentage of each lipid and the cholesterol saturation index were calculated (27-30). Bilirubin due to

Table II. Gallbladder Function

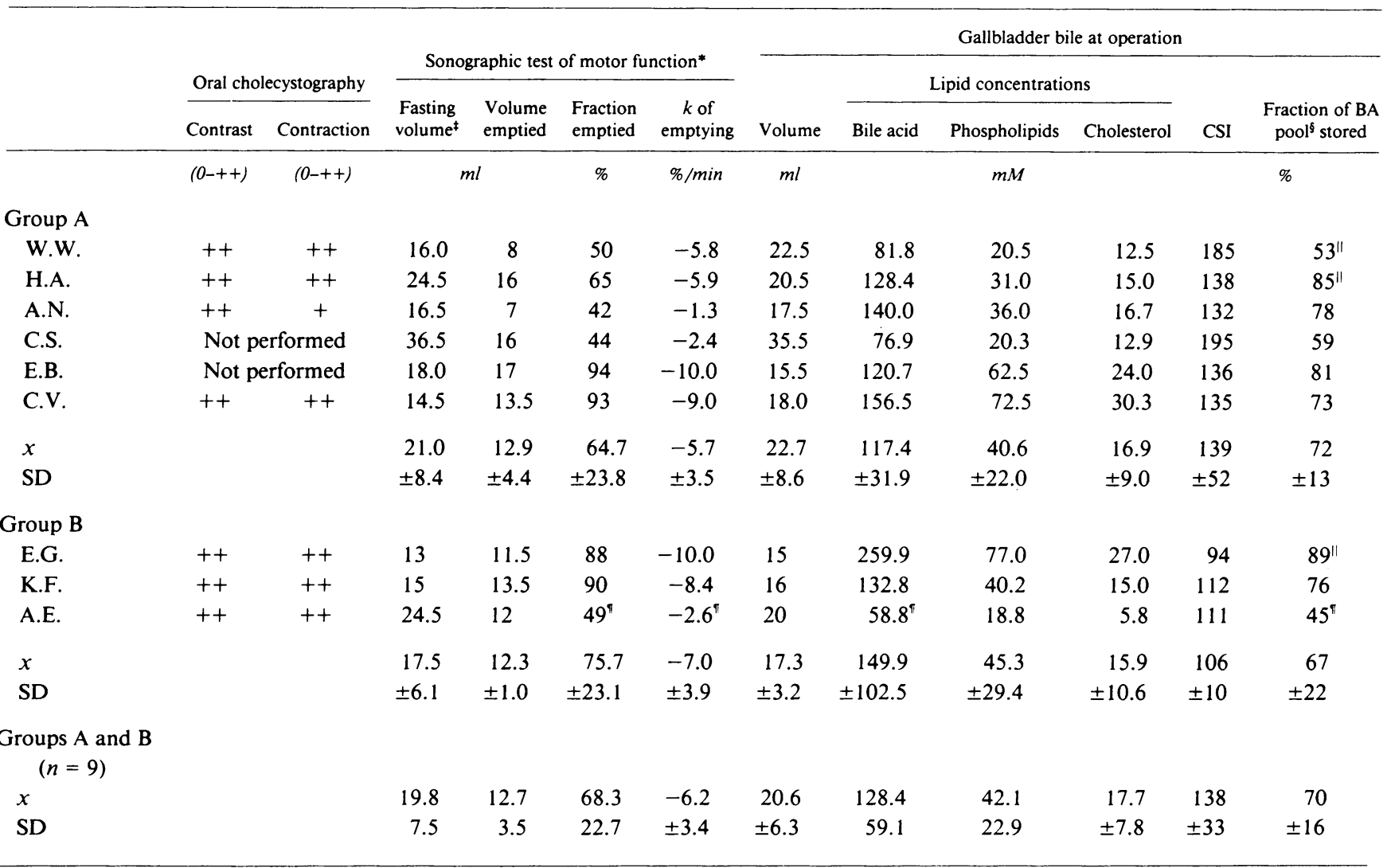

* Sonographic determination of gallbladder volumes (22) during infusion of CCK $\left(1.2 \mathrm{U} \mathrm{kg}^{-1} \cdot \mathrm{h}^{-1} \times 50 \mathrm{~min}\right)$. $\quad$ Corrected for stone volume (see Table I). ${ }^{\S}$ Bile acid pool calculated as sum of the pools of CA, CDCA, and DCA. "Calculated for the sum of CDCA and DCA pools and CDCA and DCA content of gallbladder bile. "Stone impaction in the cystic duct at $\sim 30$ min during the sonographic test, $24 \mathrm{~h}$ before surgery. Initial $k-7.3 \mathrm{~min}^{-1}$. CSI, cholesterol saturation index according to Carey and Small (29). 
Table III. Lipid Concentrations of Fasting Duodenal Bile

\begin{tabular}{|c|c|c|c|c|c|c|c|c|c|c|}
\hline \multirow[b]{2}{*}{ Subjects } & \multicolumn{5}{|c|}{ Before cholecystectomy } & \multicolumn{5}{|c|}{$7 \mathrm{wk}$ after cholecystectomy } \\
\hline & Bilirubin* & Bile salts & Phospholipids & Cholesterol & $\mathrm{CSI}^{*}$ & Bilirubin* & Bile salts & Phospholipids & Cholesterol & $\mathrm{CSI}^{*}$ \\
\hline & & & $m M$ & & $\%$ & & & $m M$ & & $\%$ \\
\hline \multicolumn{11}{|l|}{ Group A } \\
\hline w.w. & 0.038 & 4.81 & 3.3 & 1.15 & 151 & 0.009 & 12.33 & 6.1 & 1.30 & 80 \\
\hline H.A. & 0.021 & 4.78 & 1.5 & 0.38 & 79 & 0.014 & 8.31 & 2.4 & 0.50 & 64 \\
\hline A.N. & 0.005 & 2.62 & 1.4 & 0.45 & 122 & 0.012 & 16.23 & 7.0 & 2.30 & 111 \\
\hline C.S. & - & - & - & - & - & - & - & - & - & - \\
\hline E. B. & 0.005 & 2.94 & 1.2 & 0.40 & 111 & 0.007 & 6.69 & 2.8 & 0.56 & 70 \\
\hline C.V. & 0.051 & 5.25 & 2.6 & 0.82 & 114 & 0.092 & 23.72 & 6.3 & 1.75 & 83 \\
\hline \multicolumn{11}{|l|}{$(n=5)$} \\
\hline$x$ & 0.024 & 4.08 & 2.0 & 0.64 & 115 & 0.027 & 13.46 & 4.9 & 1.28 & 82 \\
\hline SD & \pm 0.020 & 1.21 & 0.9 & 0.38 & 41 & \pm 0.092 & $\pm 6.38^{8}$ & $\pm 2.2^{8}$ & $\pm 0.77^{\S}$ & $\pm 18^{8}$ \\
\hline \multicolumn{11}{|l|}{ Group B } \\
\hline E.G. & 0.037 & 10.16 & 2.7 & 0.70 & 78 & 0.039 & 20.90 & 5.8 & 0.80 & 43 \\
\hline K.F. & 0.027 & 2.58 & 1.0 & 0.20 & 67 & 0.025 & 11.69 & 3.0 & 0.65 & 65 \\
\hline A.E. & 0.031 & 13.01 & 6.0 & 1.30 & 78 & 0.015 & 17.90 & 6.9 & 1.35 & 66 \\
\hline \multicolumn{11}{|l|}{$(n=3)$} \\
\hline$x$ & 0.032 & 8.58 & 3.2 & 0.73 & 74 & 0.026 & 16.83 & 5.2 & 0.93 & 58 \\
\hline SD & \pm 0.005 & \pm 5.39 & \pm 2.5 & \pm 0.55 & \pm 6 & \pm 0.012 & \pm 4.70 & \pm 2.0 & \pm 0.37 & \pm 13 \\
\hline \multicolumn{11}{|c|}{$\begin{array}{l}\text { Groups } A \text { and } B \\
\quad(n=8)\end{array}$} \\
\hline$x$ & 0.027 & 5.77 & 2.46 & 0.68 & 100.0 & 0.027 & 14.7 & 5.0 & 1.15 & 72.8 \\
\hline SD & \pm 0.016 & \pm 3.82 & \pm 1.65 & \pm 0.39 & \pm 29.0 & \pm 0.028 & $\pm 6.0^{\prime \prime}$ & $\pm 2.0^{\prime \prime}$ & $0.64^{\prime \prime}$ & $19.6 "$ \\
\hline
\end{tabular}

* Molar ratios of bile salts/bilirubin were before vs. after surgery: $314 \pm 227$ vs. $906 \pm 483$ in group $A(P<0.05) ; 260 \pm 167$ vs. $732 \pm 400$ in group $B$, and $294 \pm 195$ vs. $841 \pm 433$ in groups $A$ and $B(P<0.02)$. ${ }^{\ddagger}$ Cholesterol saturation $(27,28)$ decreased $27 \pm 22 \%(n=8)$ in groups A and B $(P<0.02)$. ${ }^{\&} P<0.05$ as compared with preoperative value. " $P<0.02$ as compared with preoperative value.

its constant rate of hepatic secretion was used as endogenous marker of bile secretion (31).

Statistical analysis. For paired comparison, the paired $t$ test and the Wilcoxon matched-pair signed-rank test were used (32).

\section{Results}

\section{Gallbladder function}

Gallbladder motor function during CCK infusion at a physiologic rate $(21,33)$ was impaired in two patients in group $A$ (A.N. and C.S.; Table II) according to the criteria of Pomeranz and Shaffer for this CCK test (21) who defined the lower limit of normal as $19.1 \mathrm{~min} t_{1 / 2}$ of emptying (fractional rate of $3.6 \%$ per min) and a fraction of $45 \%$ emptied. Gallbladder contraction of patient A.N. was impaired to the same degree also in response to a liquid meal ( $400 \mathrm{kcal}, 40 \%$ fat; Biosorb formula; Pfrimmer \& Co., Erlangen; FRG). Motor function of the gallbladder was normal in the other four patients of group A.

Two patients of group B had well-functioning gallbladders without stones. The third patient (A.E.) contracted the gallbladder at a normal rate $k_{e}-7.3 \%$ per min during the first 20 min, but then delayed and finally stopped emptying at $35 \mathrm{~min}$. $24 \mathrm{~h}$ later at operation, her cystic duct was obstructed by a gallstone. Because the occlusion of the cystic duct had occurred after study of bile acid kinetics, we classified her gallbladder function as normal. She had pigment gallstones with small amounts of cholesterol (Table II).
The fraction of the bile acid pool stored during fasting and the concentrative function as estimated from the intraoperative gallbladder bile specimen were not impaired in groups $\mathrm{A}$ and $B$ (Table II). The reduced bile acid concentration and bile acid storage in the gallbladder of patient A.E. is explained by gallbladder hydrops lasting $24 \mathrm{~h}$ before operation.

\section{Biliary lipid composition}

In fasting duodenal bile, total bile acid concentration and bile acid/bilirubin molar ratio increased $(P<0.02)$ on the average

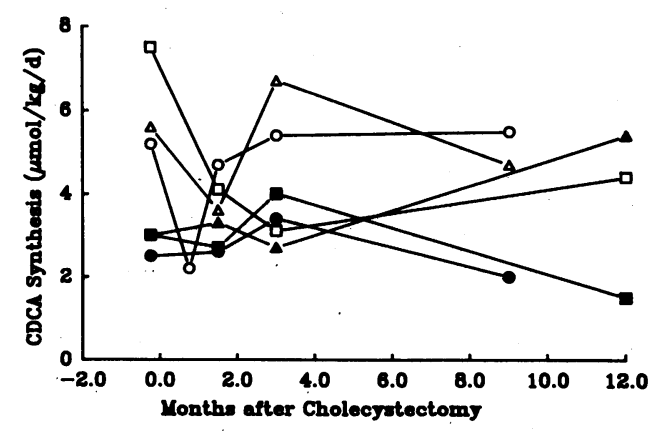

Figure 2. Time-related changes in CDCA synthesis of six patients after cholecystectomy. CDCA synthesis has returned to steady rates at $3 \mathrm{mo}$ after surgery. Synthesis rates were described in the legend to Fig. 1. 
threefold at comparable bilirubin concentration after removal of the gallbladder (Table III). The increase in molar percent bile acids lowered cholesterol saturation $(27,28)$ of unstimulated duodenal bile by $27 \%(P<0.02)$.

\section{Bile acid kinetics}

Time-related changes. Transient decreases in synthesis rate and pool size of CDCA were observed $6 \mathrm{wk}$ after cholecystectomy in some of the early studies, but at 3 and 9-12 mo after operation, synthesis or input rates and pool sizes of CDCA and DCA were at steady levels (see Fig. 2).

Primary bile acids (Table IV). CDCA kinetics were not altered by removal of the gallbladder. The kinetics of $\mathrm{CA}$, however, changed. 3 mo after cholecystectomy, synthesis rate of CA had decreased on the average by $37 \%(n=6 ; P=0.05)$ with concomitant reductions in average pool size $(-19 \%$; NS) and fractional turnover rate $(-28 \%$; NS). Hepatic synthesis of primary bile acids declined slightly from $14.0 \pm 4.8$ to $10.7 \pm 3.2$ $\mu \mathrm{mol} \cdot \mathrm{kg}^{-1} \cdot \mathrm{d}^{-1}(-18 \%$; NS) $(n=6)$ and total bile salt pool (sum of the pools of CA, CDCA, and DCA) from 52.2 \pm 9.6 to $43.9 \pm 11.3 \mu \mathrm{mol} \cdot \mathrm{kg}^{-1}(-16 \% ; P<0.05)$.

Increased levels of unconjugated primary bile acids or an increased ratio of unconjugated to conjugated bile acids (data not given) in postprandial serum, a common finding with bacterial overgrowth of the small bowel $(34,35)$, were not observed after cholecystectomy. The unconjugated fraction ac-

Table IV. Kinetics of Primary Bile Acids

\begin{tabular}{|c|c|c|c|c|c|c|c|c|c|c|c|c|}
\hline \multirow{2}{*}{$\begin{array}{l}\text { Cholic acid } \\
\qquad \text { mo after operation ... }\end{array}$} & \multicolumn{4}{|c|}{ Pool size } & \multicolumn{4}{|c|}{ Synthesis } & \multicolumn{4}{|c|}{ Rate constant } \\
\hline & - & 1.5 & 3 & $9-12$ & - & 1.5 & 3 & $9-12$ & - & 1.5 & 3 & $9-12$ \\
\hline & \multicolumn{4}{|c|}{$\mu \mathrm{mol} \cdot \mathrm{kg}^{-1}$} & \multicolumn{4}{|c|}{$\mu \mathrm{mol} \cdot \mathrm{kg}^{-1} \cdot \mathrm{d}^{-1}$} & \multicolumn{4}{|c|}{$d^{-1}$} \\
\hline \multicolumn{13}{|l|}{ Group A } \\
\hline W.W. & - & & & & - & & & & - & & & \\
\hline H.A. & - & & & & - & & & & - & & & \\
\hline A.N. & 16.9 & 10.2 & 13.5 & 15.9 & 8.3 & 5.9 & 5.4 & 5.1 & 0.49 & 0.58 & 0.40 & 0.32 \\
\hline C.S. & 31.5 & 26.8 & 16.6 & - & 7.2 & 5.1 & 5.8 & - & 0.23 & 0.19 & 0.35 & - \\
\hline E.B. & 12.9 & 10.6 & 16.4 & 10.0 & 14.3 & 8.8 & 4.4 & 7.9 & 1.11 & 0.83 & 0.27 & 0.79 \\
\hline C.V. & 17.9 & 30.4 & 13.3 & - & 8.1 & 14.3 & 7.9 & - & 0.45 & 0.47 & 0.59 & - \\
\hline \multicolumn{13}{|l|}{ Group B } \\
\hline E.G. & - & & & & - & & & & - & & & \\
\hline K.F. & 20.3 & 20.1 & 22.4 & 22.3 & 5.9 & 5.2 & 3.6 & 6.6 & 0.29 & 0.26 & 0.16 & 0.3 \\
\hline A.E. & 26.9 & 10.7 & 20.5 & - & 12.1 & 6.2 & 8.2 & - & 0.45 & 0.58 & 0.40 & - \\
\hline \multicolumn{13}{|l|}{$\begin{array}{l}\text { Groups A and B } \\
\qquad(n=6)\end{array}$} \\
\hline$x$ & 21.0 & 18.1 & 17.1 & & 9.3 & 7.6 & 5.9 & & 0.50 & 0.49 & 0.36 & \\
\hline SD & 6.9 & 9.0 & 3.7 & & 3.2 & 3.4 & 1.9 & & 0.31 & 0.23 & 0.14 & \\
\hline
\end{tabular}

Chenodeoxycholic acid

\begin{tabular}{|c|c|c|c|c|c|c|c|c|c|c|c|c|}
\hline \multicolumn{13}{|l|}{ Group A } \\
\hline W.W. & 19.4 & 15.3 & 21.6 & 18.5 & 5.2 & 4.7 & 5.4 & 5.5 & 0.27 & 0.31 & 0.25 & 0.30 \\
\hline H.A. & 14.8 & 16.3 & 12.2 & 11.8 & 2.5 & 2.6 & 3.4 & 2.0 & 0.17 & 0.15 & 0.28 & 0.17 \\
\hline A.N. & 13.4 & 16.4 & 16.6 & 14.2 & 3.0 & 3.3 & 2.7 & 5.4 & 0.22 & 0.2 & 0.16 & 0.38 \\
\hline C.S. & 18.1 & 19.9 & 13.6 & - & 3.8 & 2.8 & 4.1 & - & 0.21 & 0.14 & 0.31 & - \\
\hline E.B. & 14.5 & 14.2 & 10.4 & 12.7 & 7.5 & 4.1 & 3.1 & 4.4 & 0.52 & 0.29 & 0.30 & 0.35 \\
\hline C.V. & 13.6 & 12.3 & 6.5 & - & 5.4 & 4.8 & 4.0 & - & 0.40 & 0.39 & 0.58 & - \\
\hline$x$ & 15.6 & 15.8 & 13.5 & 14.3 & 4.6 & 3.7 & 3.8 & 4.3 & 0.30 & 0.25 & 0.31 & 0.30 \\
\hline SD & 2.5 & 2.6 & 5.2 & 3.0 & 1.8 & 1.0 & 1.0 & 1.6 & 0.13 & 0.10 & 0.14 & 0.09 \\
\hline \multicolumn{13}{|l|}{ Group B } \\
\hline E.G. & 37.6 & 23.9 & 32.0 & 24.8 & 5.6 & 3.6 & 6.7 & 4.7 & 0.15 & 0.15 & 0.21 & 0.19 \\
\hline K.F. & 16.8 & 16.8 & 19.0 & 21.2 & 3.0 & 2.7 & 4.0 & 1.5 & 0.18 & 0.16 & 0.21 & 0.07 \\
\hline A.E. & 21.5 & 20.6 & 22.0 & - & 5.6 & 6.8 & 8.1 & - & 0.26 & 0.33 & 0.37 & - \\
\hline$x$ & 25.3 & 20.4 & 24.3 & - & 4.7 & 4.4 & 6.3 & - & 0.20 & 0.21 & 0.26 & - \\
\hline SD & 10.9 & 3.6 & 6.8 & - & 1.5 & 2.2 & 2.1 & - & 0.06 & 0.10 & 0.09 & - \\
\hline \multicolumn{13}{|c|}{$\begin{array}{l}\text { Groups } \mathrm{A} \text { and } \mathrm{B} \\
\qquad(n=9)\end{array}$} \\
\hline$x$ & 18.9 & 17.3 & 17.1 & 17.2 & 4.6 & 3.9 & 4.6 & 3.9 & 0.26 & 0.24 & 0.30 & 0.24 \\
\hline $\mathrm{SD}$ & \pm 7.6 & \pm 3.6 & \pm 7.6 & \pm 5.2 & 1.6 & 1.4 & 1.8 & 1.7 & 0.12 & \pm 0.09 & \pm 0.12 & 0.12 \\
\hline
\end{tabular}


Table V. Kinetics of Deoxycholic Acid

\begin{tabular}{|c|c|c|c|c|c|c|c|c|c|c|c|c|}
\hline \multirow[b]{2}{*}{ mo after operation } & \multicolumn{4}{|c|}{ Pool size } & \multicolumn{4}{|c|}{ Input rate } & \multicolumn{4}{|c|}{ Rate constant } \\
\hline & 0 & 1.5 & 3 & $9-12$ & 0 & 1.5 & 3 & $9-12$ & 0 & 1.5 & 3 & $9-12$ \\
\hline & \multicolumn{4}{|c|}{$\mu \mathrm{mol} \cdot \mathrm{kg}^{-1}$} & \multicolumn{4}{|c|}{$\mu \mathrm{mol} \cdot \mathrm{kg}^{-1} \cdot \mathrm{d}^{-1}$} & \multicolumn{4}{|c|}{$d^{-1}$} \\
\hline \multicolumn{13}{|l|}{ Group A } \\
\hline W.W. & 13.3 & 9.4 & 10.5 & 5.2 & 2.6 & 2.4 & 2.0 & 2.4 & 0.20 & 0.25 & 0.19 & 0.46 \\
\hline H.A. & 9.2 & 11.8 & 8.5 & 8.2 & 1.8 & 1.3 & 2.0 & 1.5 & 0.28 & 0.11 & 0.24 & 0.18 \\
\hline A.N. & 14.6 & 10.9 & 14.2 & 13.7 & 4.5 & 4.2 & 4.8 & 4.6 & 0.31 & 0.38 & 0.34 & 0.25 \\
\hline C.S. & 15.9 & 9.8 & 21.2 & - & 3.5 & 3.6 & 5.1 & - & 0.22 & 0.37 & 0.24 & - \\
\hline E.B. & 14.4 & 20.9 & 4.8 & 24.4 & 5.7 & 5.0 & 1.6 & 7.8 & 0.40 & 0.25 & 0.34 & 0.32 \\
\hline C.V. & 19.0 & 12.0 & 16.5 & - & 5.4 & 5.3 & 7.9 & - & 0.28 & 0.44 & 0.48 & - \\
\hline$x$ & 14.4 & 12.5 & 12.6 & 12.9 & 3.9 & 3.6 & 3.9 & 4.1 & 0.28 & 0.30 & 0.31 & 0.30 \\
\hline SD & \pm 3.2 & \pm 4.3 & \pm 5.0 & \pm 8.5 & \pm 1.6 & \pm 1.5 & \pm 2.5 & \pm 2.8 & \pm 0.07 & \pm 0.12 & \pm 0.10 & \pm 0.12 \\
\hline \multicolumn{13}{|l|}{ Group B } \\
\hline E.G. & 4.7 & 6.4 & 3.2 & 8.2 & 1.4 & 1.7 & 1.3 & 3.5 & 0.24 & 0.27 & 0.41 & 0.42 \\
\hline K.F. & 10.8 & 2.0 & 3.8 & 2.0 & 1.1 & 0.3 & 0.8 & 0.6 & 0.10 & 0.15 & 0.20 & 0.31 \\
\hline A.E. & 13.9 & 13.1 & 20.9 & - & 5.4 & 4.2 & 5.2 & - & 0.39 & 0.32 & 0.25 & - \\
\hline$x$ & 9.8 & 7.2 & 9.3 & & 2.6 & 2.1 & 2.4 & & 0.24 & 0.25 & 0.29 & \\
\hline SD & \pm 4.7 & \pm 5.6 & \pm 10.1 & & \pm 2.4 & \pm 2.0 & \pm 2.4 & & \pm 0.15 & \pm 0.09 & \pm 0.11 & \\
\hline \multicolumn{13}{|l|}{$\begin{array}{l}\text { Groups } \mathrm{A} \text { and } \mathrm{B} \\
\quad(n=9)\end{array}$} \\
\hline$x$ & 12.9 & 10.7 & 11.5 & 10.3 & 3.5 & 3.1 & 3.4 & 3.4 & 0.27 & 0.28 & 0.30 & 0.32 \\
\hline SD & \pm 4.2 & \pm 5.1 & 7.1 & 7.9 & 1.8 & 1.8 & 2.4 & 2.6 & \pm 0.09 & \pm 0.11 & \pm 0.10 & \pm 0.10 \\
\hline
\end{tabular}

counted for $44 \pm 24 \%$ of CA in postprandial serum after cholecystectomy vs: $59 \pm 27 \%$ before surgery, and for $36 \pm 27 \%$ vs. $45 \pm 22 \%$ of CDCA, respectively ( $n=9$; groups A and B).

Secondary bile acids. Pool size, FTR, and input rate of DCA were not altered by removal of the gallbladder (Table V; groups A and B). DCA pool size was correlated to DCA input rate in the same positive linear fashion before and after cholecystectomy $(P<0.01)$. In accordance with the individual bile acid pools, the fraction of DCA in unstimulated duodenal bile did not change, whereas the contribution of CA decreased by $6.1 \%$ (Table VI). Also 9 mo after surgery, as studied in the first three patients (W.W., H.A., E.G.), there was no increase in the fraction of DCA (11.8 \pm 6.6 vs. $13.8 \pm 7.3 \%$, preoperatively), or of secondary bile acids ( $11.8 \pm 6.6$ vs. $17.3 \pm 10.0 \%)$, nor in the molar ratio of DCA/CA $(0.27 \pm 0.21$ vs. $0.40 \pm 0.38$, preoperatively).

Transfer of CA to the DCA pool. The fraction of CA serving as precursor for the DCA pool (DCA input/CA synthesis) increased by $30 \%(P<0.05)$ from $46 \pm 16$ to $66 \pm 32 \%$ (Table VII). This could be directly shown by more rapid and increased transfer of ${ }^{13} \mathrm{C}$ label from ${ }^{13} \mathrm{C}$-CA to the DCA pool (Fig. 3). After removal of the gallbladder, ${ }^{13} \mathrm{C}$ label administered orally as $24-{ }^{13} \mathrm{C}$-CA appeared as ${ }^{13} \mathrm{C}$-DCA more rapidly and peaked there already $2 \mathrm{~d}$ after oral intake. By comparison, this peak occurred at $\sim 4 \mathrm{~d}$ when the gallbladder was intact. After cholecystectomy, positive correlations existed between CA synthe-

Table VI. Bile Acid Pattern in Fasting Duodenal Bile

\begin{tabular}{|c|c|c|c|c|c|c|c|}
\hline & \multirow[b]{2}{*}{$n$} & \multicolumn{5}{|c|}{$\%$ of total bile acids } & \multirow[b]{2}{*}{$\mathrm{DCA} / \mathrm{CA}$} \\
\hline & & $\mathrm{CDCA}$ & $\mathrm{CA}$ & DCA & UDCA & LCA & \\
\hline \multicolumn{8}{|c|}{ Before cholecystectomy } \\
\hline Group A & 5 & $29.2 \pm 9.2$ & $47.1 \pm 10.7$ & $21.8 \pm 8.0$ & $1.7 \pm 2.9$ & $0.3 \pm 0.7$ & $0.54 \pm 0.31$ \\
\hline Group B & 3 & $38.0 \pm 3.7$ & $42.5 \pm 7.2$ & $16.3 \pm 8.9$ & $2.6 \pm 2.3$ & $0.7 \pm 1.3$ & $0.42 \pm 0.31$ \\
\hline Groups A and B & 8 & $32.5 \pm 8.6$ & $45.3 \pm 9.7$ & $19.8 \pm 8.2$ & $2.0 \pm 2.6$ & $0.5 \pm 0.9$ & $0.50 \pm 0.29$ \\
\hline \multicolumn{8}{|c|}{ After cholecystectomy* } \\
\hline Group A & 5 & $37.2 \pm 5.0$ & $38.1 \pm 9.7^{\ddagger}$ & $22.3 \pm 6.9$ & $2.8 \pm 2.2$ & $1.1 \pm 1.2$ & $0.60 \pm 0.28$ \\
\hline Group B & 3 & $37.3 \pm 5.5$ & $41.0 \pm 8.6$ & $14.9 \pm 13.6$ & $6.7 \pm 3.4$ & 0 & $0.42 \pm 0.44$ \\
\hline Groups A and B & 8 & $37.3 \pm 4.8$ & $39.2 \pm 8.8$ & $18.5 \pm 9.2$ & $4.3 \pm 3.2$ & $0.7 \pm 1.1$ & $0.53 \pm 0.33$ \\
\hline
\end{tabular}

${ }^{\ddagger} P<0.05$ as compared with preoperative percentage. $* 7 \mathrm{wk}$ after surgery. LCA, lithocholic acid; UDCA, ursodeoxycholic acid. 
Table VII. Fraction of Cholic Acid Transferred to the Deoxycholic Acid Pool*

\begin{tabular}{lrrrr} 
& & \multicolumn{3}{c}{ Mo after cholecystectomy } \\
\cline { 3 - 5 } Subject & Before & 1.5 & 3 & 12 \\
\hline & & \multicolumn{4}{c}{$\%$} \\
A.N. & 54 & 71 & 89 & 90 \\
C.S. & 49 & 71 & 88 & - \\
E.B. & 40 & 57 & 36 & 99 \\
C.V. & 67 & 37 & 100 & - \\
K.F. & 19 & 6 & 22 & 9 \\
A.E. & 45 & 68 & 63 & - \\
$x$ & 46 & 52 & $66^{\ddagger}$ & - \\
SD & \pm 16 & \pm 26 & \pm 32 & -
\end{tabular}

* Calculated from bile acid kinetics as DCA input rate divided by CA synthesis rate times 100 .

${ }^{\ddagger} P<0.05$ as compared with preoperative percentage (paired $t$ test).

sis rate and DCA input rate $(P<0.02)$ and between CA synthesis rate and DCA pool size $(P<0.01)$. Before cholecystectomy, these parameters were not significantly correlated.

\section{Discussion}

To investigate the role of the gallbladder in bile acid metabolism, we have simultaneously studied pool size and synthesis of the three major bile acids before cholecystectomy and repeatedly in the first year after operation. Bile acids increased in fasting duodenal bile in absolute concentration and relative to bilirubin, consistent with their increased biliary output and enterohepatic cycling after removal of the gallbladder (13). Accordingly, cholesterol saturation of fasting bile was decreased, as previously summarized by Palmer (36). Increased enterohepatic cycling had not altered size or turnover of the CDCA pool. CA synthesis, however, had declined resulting in decreased pool size and FTR. Contrary to the initial hypothesis, size and input of the DCA pool did not increase, although its precursor CA was transferred to the DCA pool at a higher fractional rate.

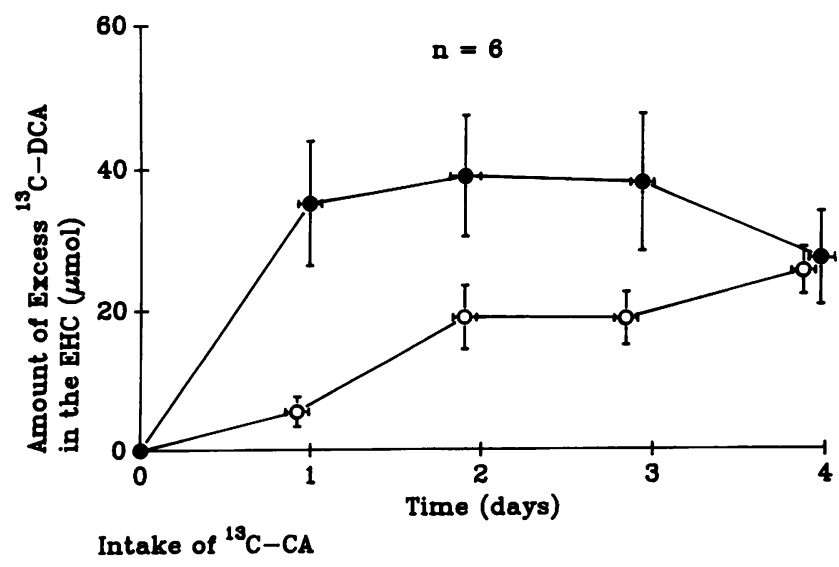

Figure 3. Time course of the amount of excess ${ }^{13} \mathrm{C}$-labeled DCA in the DCA pool after oral intake of $50 \mathrm{mg}{ }^{13} \mathrm{C}$-cholic acid in six subjects before $(0)$ and after $(\bullet)$ cholecystectomy $(X \pm S E M)$. Enhanced formation and increased input of ${ }^{13} \mathrm{C}$-DCA after cholecystectomy. For calculation see Methods.
All our patients had functioning gallbladders before surgery (Table II). Factors other than removal of the gallbladder were balanced. Thus, the intraindividual comparison $(3,14)$ was more reliable than a group comparison between cholecystectomized gallstone patients and healthy controls (4), controls with other diseases $(5,37)$, or even disease controls $(15,38$, $39)$. In contrast to some of the previous studies $(4,5,15$, 37-39), we had excluded other factors known to influence bile acid metabolism such as older age, hyperlipidemias, obesity, cholangitis, diseases of the liver and small bowel, and intake of contraceptive steroids. All patients had comparable body weight, cholesterol intake, and bowel habits before and after cholecystectomy (Table I). The technique to estimate simultaneously the kinetics of all three major bile acids had been validated (20); in both the presence and absence of the gallbladder it yielded monoexponential isotopic decay curves. Because we had administered unconjugated marker bile acids, the true turnover of the respective bile acid pools was estimated (40); some other studies had used conjugated marker bile acids $(4,5)$, which do not completely equilibrate with the endogenous pool (40). In our study, the daily serum samples for measurement of isotope ratios were obtained after the evening meal, when the marker bile acids were well mixed with the endogenous bile acids. This appears superior to previous kinetic studies (41) that used CCK-stimulated gallbladder bile before surgery, but unstimulated duodenal bile after surgery $(3-5,15)$. In unstimulated duodenal bile, specific activity of primary bile acids probably is not in isotopic equilibrium with that of the pool during morning hours, when daily synthesis of primary bile acids peaks (42).

After cholecystectomy, the total bile acid pool shrank by $16 \%(P<0.05)$. This was caused by a reduction of the CA pool. Similar observations have been made in other studies $(4,15$, 38 ), but this had always been associated with increased fractional turnover of the bile acid pool $(3-5,15)$. Accordingly, the reduction in bile acid pool size has been explained by enhanced loss of primary bile acids from the enterohepatic circulation $(15,38)$. By contrast, using advanced techniques, we observed reduced fractional turnover and synthesis of CA.

Previous studies based on group comparison $(4,5,15)$ do not allow definitive conclusions on the effects of cholecystectomy on bile acid metabolism: Pomare and Heaton (4) and Hepner et al. (5) had used conjugated marker bile acids that were turned over more rapidly after cholecystectomy due to increased bacterial deconjugation of bile acids (43). Roda et al. (15) had observed a small CA pool with enhanced fractional turnover rate in cholecystectomized patients, but the FTR was enhanced in a subgroup of cholecystectomized patients only, who had bile acid malabsorption.

Only Almond et al. (3) had studied the kinetics of CA and CDCA in 10 patients before and after cholecystectomy. They reported increased fractional turnover of $\mathrm{CA}$ and CDCA, but no change in pool sizes or synthesis of the two primary bile acids. Further analysis of their data reveals two subgroups of five patients each that differed in their CA metabolism before surgery. The first group (subjects $1,2,5,6$, and 7) with very low $C A$ synthesis $(141 \pm 7 \mathrm{mg} / 70 \mathrm{~kg} / \mathrm{d})$ doubled its synthesis rate $(274 \pm 77 \mathrm{mg} / 70 \mathrm{~kg} / \mathrm{d} ; P<0.05)$ increasing the size $(+64 \%)$ and the fractional turnover rate $(+37 \%)$ of the CA pool and the estimated pool of secondary bile acids $(0.24 \pm 0.12$ vs. $0.36 \pm 0.15 \mathrm{mg} / 70 \mathrm{~kg}$ ). Unfortunately, we do not have additional characteristics of these patients who had repressed CA 
Table VIII. Studies of Bile Acid Kinetics with and without Gallbladder (Mean Values)

\begin{tabular}{|c|c|c|c|c|c|c|c|c|c|c|}
\hline & \multirow[b]{2}{*}{ Marker } & \multirow[b]{2}{*}{ Comparison } & \multirow[b]{2}{*}{ Pool } & \multirow[b]{2}{*}{ FTR } & \multirow[b]{2}{*}{ Turnover } & \multicolumn{4}{|c|}{ Bile acid pattern (\%) in bile } & \multirow[b]{2}{*}{ DCA/CA ratio } \\
\hline & & & & & & CA & CDCA & DCA & Others & \\
\hline & & $n$ & $g$ & $d^{-1}$ & $g / d$ & & & & & \\
\hline \multirow[t]{5}{*}{ Almond (1973) } & $24-{ }^{14} \mathrm{C}-\mathrm{CA}$ & Intraindividual & & & & & & & & \\
\hline & & Before CCX (10) & 0.37 & 0.63 & 0.208 & 35 & 43 & 20 & 3 & 0.57 \\
\hline & & After CCX & 0.34 & $0.81^{*}$ & 0.255 & 28.5 & 38.5 & $30^{*}$ & 3 & 1.05 \\
\hline & $24-{ }^{14} \mathrm{C}-\mathrm{CDCA}$ & Before CCX (10) & 0.39 & 0.39 & 0.143 & & & & & \\
\hline & & After CCX & 0.33 & $0.50^{*}$ & 0.155 & & & & & \\
\hline \multirow[t]{3}{*}{ Pomare $^{\ddagger}(1973)$} & Tauro $24-{ }^{14} \mathrm{C}-\mathrm{CA}$ & Interindividual & & & & & & & & \\
\hline & & Healthy (10) & 0.36 & 0.42 & 0.149 & 38 & 35 & 27 & 0 & 0.71 \\
\hline & & CCX XGS (10) & 0.19 & 0.72 & 0.142 & 32.5 & 23 & 45 & 0 & 1.38 \\
\hline \multirow[t]{4}{*}{ Hepner (1974) } & $1-{ }^{14} \mathrm{C}-\mathrm{Glyco}-24-{ }^{3} \mathrm{H}-\mathrm{CA}$ & Interindividual & & & & & & & & \\
\hline & & Healthy $(12)^{\S}$ & 1.11 & 0.35 & 0.347 & 48 & 30 & 21 & 1 & 0.44 \\
\hline & & XGS $(13)^{\S}$ & $0.67^{*}$ & 0.43 & 0.275 & 42 & 28 & 29 & 1 & 0.69 \\
\hline & & CCX XGS $(10)^{\S}$ & $0.75^{*}$ & 0.44 & 0.333 & $24.5^{*}$ & 29 & 37 & 10 & 1.51 \\
\hline \multirow[t]{4}{*}{ Roda (1978) } & $24-{ }^{14} \mathrm{C}-\mathrm{CA}$ & Interindividual & & & & & & & & \\
\hline & & Healthy (10) & 0.80 & 0.28 & 0.239 & 40 & 40.5 & 18 & 1.5 & 0.45 \\
\hline & & XGS (10) & 0.50 & 0.38 & 0.117 & 24 & 36 & 35 & 5 & 1.46 \\
\hline & & CCX" XGS (10) & $0.40^{*}$ & $0.56^{*}$ & 0.233 & 20.5 & 40 & 33 & 6.5 & 1.61 \\
\hline \multirow{7}{*}{$\begin{array}{l}\text { This study } \\
\text { (groups A and B) }\end{array}$} & $24-{ }^{13} \mathrm{C}-\mathrm{CA}$ & Intraindividual & & & & & & & & \\
\hline & & Before CCX (6) & $0.60^{\S}$ & 0.50 & 0.266 & 45 & 33 & 20 & 2 & 0.50 \\
\hline & & After CCX & $0.49^{\S}$ & 0.36 & $0.169^{*}$ & 39 & 37 & 19 & 5 & 0.53 \\
\hline & $24-{ }^{13} \mathrm{C}-\mathrm{CDCA}$ & Before CCX (9) & $0.52^{\S}$ & 0.26 & 0.128 & & & & & \\
\hline & & After CCX & $0.47^{\S}$ & 0.30 & 0.126 & & & & & \\
\hline & $2,4-{ }^{2} \mathrm{H}_{4}-\mathrm{DCA}$ & Before CCX (9) & $0.34^{\S}$ & 0.27 & 0.096 & & & & & \\
\hline & & After CCX & $0.32^{\S}$ & 0.30 & 0.093 & & & & & \\
\hline
\end{tabular}

* Significantly different from control. ${ }^{\ddagger}$ Only one of four additional patients studied before and after cholecystectomy had clearly decreased pool size and FTR, whereas changes in the other three were minor. ${ }^{8}$ Converted to average body weight of $70 \mathrm{~kg}$. " 5 of the 10 patients probably had bile acid malabsorption (increased fecal output of ${ }^{14} \mathrm{C}$ ). Abbreviations: CCX, cholecystectomy; XGS, cholesterol gallstones; BA, bile acid.

synthesis before surgery. The other subgroup had higher CA synthesis $(340 \pm 119 \mathrm{mg} / 70 \mathrm{~kg} / \mathrm{d} ; P<0.005)$, which was in a similar range as that of our patients (see Table VIII). They responded to cholecystectomy in the same way as our patients: synthesis of CA decreased by $38 \%$ (to $169 \pm 59 \mathrm{mg} / 70 \mathrm{~kg} / \mathrm{d} ; P$ $<0.05$ ) and pool size by $47 \%$ without significant increase in fractional turnover rate $\left(0.64 \pm 0.32\right.$ vs. $\left.0.78 \pm 0.38 \mathrm{~d}^{-1}\right)$; the estimated pool of secondary bile acids remained unaltered $(0.26 \pm 0.14$ vs. $0.24 \pm 0.09 \mathrm{mg} / 70 \mathrm{~kg}$ after cholecystectomy). Thus, even Almond's data suggest that cholecystectomy leads to suppression of CA synthesis, if it is not repressed a priori.

The widely accepted hypothesis that cholecystectomy increases formation and pool size of secondary bile acids, mainly DCA, originated from studies of bile acid pattern of duodenal bile (3-5) (Table VIII). Two of these studies $(4,5)$ using an inappropriate control group reported a higher DCA fraction in bile of cholecystectomized patients. Roda et al. (15), who had studied an appropriate disease control group, found the DCA content of bile elevated to the same extent in the presence as in the absence of the gallbladder. Three studies, including our own, $(3,14)$ have compared biliary bile acids in the same patients before and after cholecystectomy. In Van der Linden's (14) and our patients, cholecystectomy did not increase DCA in bile (Table VIII). As already mentioned, one subgroup of Almond's (3) patients increased the synthesis of CA and the pool of secondary bile acids after cholecystectomy, whereas the other subgroup, like our patients, responded to cholecystectomy with a decrease in CA synthesis at unaltered secondary bile acids.

We have directly measured the kinetics of DCA before and after cholecystectomy. Despite reduced synthesis and pool size of CA, input, and size of the DCA pool did not change, because the fraction of CA transferred to the DCA pool increased (Table VII). This has also been shown directly by more rapid and increased influx of ${ }^{13} \mathrm{C}$ label into the DCA pool after intake of ${ }^{13} \mathrm{C}$-CA (Fig. 3). Because under normal conditions practically all CA ( $\geq 95 \%)$ is dehydroxylated to DCA in the colon (44), increased fractional transfer must have resulted from enhanced fractional absorption of newly formed DCA.

Two mechanisms are possible: increased fractional absorption of DCA from the colon or formation of DCA in the ileum. Fractional absorption of DCA from the large bowel is mainly determined by colonic transit time (45). However, increased absorption of DCA from the colon, the usual site of DCA formation (46), could not sufficiently explain the more rapid transfer of CA to the DCA pool (Fig. 3), because the synthesis of CA (reduction of both pool size and fractional turnover) and consequently the loss of CA into the colon were reduced. Our findings could be well explained by the assumption that after cholecystectomy a larger fraction of DCA is formed in the 
ileum, where it is very efficiently absorbed by the active transport mechanism for bile acids (47). By contrast, in normal man only very little DCA $(<5 \%)$ is formed in the ileum $(45)$ Continuous presence of $\mathrm{CA}$ in the lower ileum and prolonged small bowel transit after cholecystectomy (48) could facilitate formation of DCA in the ileum by $7 \alpha$-dehydroxylating species of anaerobic bacteria (49) that are found in substantial concentrations in the distal ileum (50).

In conclusion, the following hypothesis is consistent with our data as well as that of most previous studies $(3,4,13,14)$ : cholecystectomy enhances enterohepatic cycling of bile acids in the fasting state. This does not increase their loss from the enterohepatic circulation, but reduces the synthesis of $\mathrm{CA}$, consistent with the concept that synthesis of $\mathrm{CA}$ is under control of the transhepatic flux of bile acids. Prolonged exposure of CA to anaerobic bacteria, presumably in the distal ileum, leads to earlier $7 \alpha$-dehydroxylation of $\mathrm{CA}$ and increased fractional absorption of newly formed DCA. Together, these changes result in a slight reduction in the $\mathrm{CA}$ and in the total bile acid pool, whereas turnover and size of the DCA pool remain constant.

\section{Acknowledgments}

We thank Ms. Dorothe Nissle for evaluation of the dietary records. The skillful technical assistance of Mrs. Elke Koenig, Mrs. Renate Artmann, Ms. Heide Krahl, and Mrs. Gundula Dyck is gratefully acknowledged.

This work was supported by grant Be 890/2-1 from the Deutsche Forschungsgemeinschaft.

\section{References}

1. Hofmann, A. F. 1984. Medical treatment of cholesterol gallstones by bile desaturating agents. 1984. Hepatology (Baltimore). 4:199-208.

2. Sauerbruch, T., M. Delius, G. Paumgartner, J. Holl, O. Wess, W. Weber, W. Hepp, and W. Brendl. 1986. Fragmentation of gallstones by extracorporeal shock waves. $N$. Engl. J. Med. 314:818-822.

3. Almond, H. R., Z. R. Vlahcevic, C. C. Bell, Jr., D. H. Gregory, and L. Swell. 1973. Bile acid pools, kinetics and biliary lipid composition before and after cholecystectomy. N. Engl. J. Med. 289:12131216.

4. Pomare, E. W., and K. W. Heaton. 1973. The effect of cholecystectomy on bile salt metabolism. Gut. 14:753-762.

5. Hepner, G. W., A. F. Hofmann, J. R. Malagelada, P. A. Szczepanik, and P. D. Klein. 1974. Increased bacterial degradation of bile acids in cholecystectomized patients. Gastroenterology. 66:556-564.

6. Linas, D. A., W. M. O'Fallon, R. W. Beart Jr., C. M. Beard, M. B. Dockerty, and L. T. Kurland. 1981. Cholecystectomy and carcinoma of the colon. Lancet. ii:379-381.

7. Vernick, L. J., and L. H. Kuller. 1982. A case-control study of cholecystectomy and right-sided colon cancer. Am. J. Epidemiol. 116:86-101.

8. Mannes G. A., M. Weinzierl, F. Stellaard, C. Thieme, B. Wiebecke, and G. Paumgartner. 1984. Adenomas of the large intestine after cholecystectomy. Gut. 25:863-866.

9. Adami, H.-O., O. Meirink, S. Gustavsson, O. Nyren, U.-B. Krusemo. 1983. Colorectal cancer after cholecystectomy: absence of risk increase within 11-14 years. Gastroenterology. 85:859-865.

10. Ericksson, S. G., and C. G. Lindström. 1984. Lack of relationship between cholecystectomy and colorectal cancer. Scand. J. Gastroenterol. 19:977-982.

11. Reddy, B. S., K. Watanabe, J. H. Weisburger, and E. L. Wynder. 1977. Promoting effect of bile in colon carcinogenesis in germfree and conventional F344 rats. Cancer Res. 37:3238-3242.
12. Werner, B., K. deHeer, and H. Mitschke. 1977. Cholecystectomy and carcinoma of the colon. An experimental study. Z. Krebsforsch. 88:223-230.

13. Malagelada, J. R., W. V. L. Go., W. J. Summerskill, and W. S. Gamble. 1973. Bile acid secretion and biliary bile acid composition altered by cholecystectomy. Dig. Dis. Sci. 18:455-45.

14. Van der Linden, W., B. Katzenstein, and F. Nakayama. 1983. The possible carcinogenic effect of cholecystectomy. Cancer. 52:1265-1268.

15. Roda, E., R. Aldini, G. Mazzella, A. Roda, C. Sama, D. Festi, and L. Barbara. 1978. Enterohepatic circulation of bile acids after cholecystectomy. Gut. 19:640-649.

16. Van der Werf, S. D. J., A. W. M. Huijbregts, H. L. M. Lamers, G. P. Van Berge Henegouwen, and J. H. M. Van Tongeren. 1981. Age dependent differences in human bile acid metabolism and $7 \alpha$-dehydroxylation. Eur. J. Clin. Invest. 11:425-431.

17. White, E. C., D. J. McNamara, and E. H. Ahrens. 1981. Validation of a dietary record system for the estimation of daily cholesterol intake in individual outpatients. Am. J. Clin. Nutr. 34:199-203.

18. Aign, H.-D. W., I. Elmadfa, E. Muskat, and M. Westhoff, editors. 1984. Die Grosse Naehrwerttabelle. Graefe und Unzer Verlag, Munich. 1-48.

19. Stellaard, F., M. Sackmann, T. Sauerbruch, and G. Paumgartner. 1984. Simultaneous determination of cholic acid and chenodeoxycholic acid pool sizes and fractional turnover rates in human serum using ${ }^{13}$ C-labeled bile acids. J. Lipid Res. 25:1313-1319.

20. Stellaard, F., M. Sackmann, F. Berr, and G. Paumgartner. 1987. Simultaneous determination of pool sizes and fractional turnover rates of deoxycholic acid in man by isotope dilution with ${ }^{2} \mathrm{H}$ and ${ }^{13} \mathrm{C}$ labels and serum sampling. Biochem. Environ. Mass Spectr. 14:609-611.

21. Pomeranz, I. S., and E. A. Shaffer. 1985. Abnormal gallbladder emptying in a subgroup of patients with gallstones. Gastroenterology. 88:787-791.

22. Everson, G. T., D. Z. Braverman, M. L. Johnson, and F. Kern Jr. 1980. A critical evaluation of real-time ultrasonography for the study of gallbladder volume and contraction. Gastroenterology. 79:40-46.

23. Sauerbruch, T., F. Stellaard, N. Soehendra, and G. Paumgartner. 1983. Cholesteringehalt von Gallengangssteinen. Dtsch. Med. Wochenschr. 29:1099-1102.

24. Wahlefeld, A. W., G. Herz, and E. Bernt. 1972. Modification of the Malloy-Evelyn method for a simple, reliable determination of total bilirubin in serum (abstract). Scand. J. Clin. Lab. Invest. 29:(Suppl. 126): 11-12.

25. Abell, L. L., B. B. Levy, B. B. Brodie, and F. E. Kendall. 1952. A simplified method for the estimation of total cholesterol in serum and demonstration of its specificity. J. Biol. Chem. 195:357-359.

26. Bartlett, G. R. 1959. Phosphorus assay in column chromatography. J. Biol. Chem. 234:466-468.

27. Admirand, W. H., and D. M. Small. 1968. The physical chemical basis of cholesterol gallstone formation in man. J. Clin. Invest. 47:1043-1052.

28. Holzbach, R. T., M. Marsh, M. Olsewszki, and K. R. Holan. 1973. Cholesterol solubility in bile. Evidence that supersaturated bile is frequent in healthy man. J. Clin. Invest. 52:1467-1479.

29. Carey, M. C., and D. M. Small. 1978. The physical chemistry of cholesterol solubility in bile. J. Clin. Invest. 61:998-1026.

30. Kuroki, S., B. I. Cohen, M. C. Carey, and E. H. Mosbach. 1986. Rapid computation with the personal computer of the percent cholesterol saturation of bile samples. J. Lipid Res. 27:442-446.

31. Mok, H. I., K. von Bergmann, and S. M. Grundy. 1980. Kinetics of the enterohepatic circulation during fasting: biliary secretion and gallbladder storage. Gastroenterology. 78:1023-1033.

32. Snedecor, G. W., and W. G. Cochran. 1982. Statistical Methods. 7th ed. Iowa State University Press, Ames, Iowa. 83-89 and 141-143.

33. Hopman, W. P. M., P. J. S. M. Kerstens, J. B. M. J. Jansen, G. 
Rosenbusch, and C. B. H. W. Lamers. 1985. Effect of graded physiologic doses of cholecystokinin on gallbladder contraction measured by ultrasonography. Gastroenterology. 89:1242-1247.

34. Fromm, H., and A. F. Hofmann. 1971. Breath test for altered bile acid metabolism. Lancet. ii:621-625.

35. Stellaard, F., T. Sauerbruch, C. H. Luderschmidt, B. Leisner, and G. Paumgartner. 1987. Intestinal involvement in progressive systemic sclerosis detected by increased unconjugated serum bile acids. Gut. 28:446-450.

36. Palmer, R. H. 1976. The gallbladder and bile composition. (editorial). Dig. Dis. Sci. 21:795-796.

37. Shaffer, E. A., J. W. Braasch, and D. M. Small. 1972. Bile composition at and after surgery in normal persons and patients with gallstones. N. Engl. J. Med. 287:1317.

38. Shaffer, E. A., and D. M. Small. 1977. Biliary lipid secretion in cholesterol gallstone disease. The effect of cholecystectomy and obesity. J. Clin. Invest. 59:828-840.

39. McDougall, R. M., K. Walker, and D. G. Thurston. 1975. Prolonged secretion of lithogenic bile after cholecystectomy. Ann. Surg. 182:150-152.

40. Hoffman, N. E., and A. F. Hofmann. 1974. Measurement of bile acid kinetics by isotope dilution in man. Gastroenterology. 67:314-323.

41. Lindstedt, S. 1957. The turnover of cholic acid in man. Acta Physiol. Scand. 40:1-9.
42. Duane, W. C., D. G. Levitt, S. M. Mueller, and J. C. Behrens. 1983. Regulation of bile acid synthesis in man. J. Clin. Invest. 72:1930-1936.

43. Hepner, G. W., A. F. Hofmann, and P. J. Thomas. 1972. Metabolism of steroid and amino acid moieties of conjugated bile acids in man. J. Clin. Invest. 51:1898-1905.

44. Salvioli, G., R. Salati, M. Bondi, A. Fratalocchi, B. M. Sala, and A. Gibertini. 1982. Bile acid transformation by the intestinal flora and cholesterol saturation in bile. Effects of steptococcus faecium administration. Digestion. 23:80-88.

45. Marcus, S. N., and K. W. Heaton. 1986. Intestinal transit, deoxycholic acid and the cholesterol saturation of bile-three inter-related factors. Gut. 27:550-558.

46. Morris, J. S., T. S. Low-Beer, and K. W. Heaton. 1973. Bile salt metabolism and the colon. Scand. J. Gastroenterology. 8:425-431.

47. Krag, E., and S. F. Phillips. 1974. Active and passive bile acid absorption in man. J. Clin. Invest. 53:1686-1694.

48. Penagini, R., R. C. Spiller, J. J. Misiewicz, P. G. Frost, and D. B. A. Silk. 1988. Effect of cholecystectomy on mouth-to-cecum transit of a liquid meal. Dig. Dis. Sci. 33:19-22.

49. Hill, M. J., and B. S. Drasar. 1968. Degradation of bile salts by human intestinal bacterial. Gut. 9:22-27.

50. Simon, G. L., and S. L. Gorbach. 1984. Intestinal flora in health and disease. Gastroenterology. 86:174-193. 